Article

\title{
Sustainable Anodes for Lithium- and Sodium-Ion Batteries Based on Coffee Ground-Derived Hard Carbon and Green Binders
}

\author{
Hamideh Darjazi, Antunes Staffolani (D, Leonardo Sbrascini, Luca Bottoni, Roberto Tossici and \\ Francesco Nobili *
}

Chemistry Division, School of Science and Technology, University of Camerino, 62032 Camerino, Italy; hamideh.darjazi@unicam.it (H.D.); antunes.staffolani@unicam.it (A.S.); leonardo.sbrascini@unicam.it (L.S.); luca.bottoni@unicam.it (L.B.); roberto.tossici@unicam.it (R.T.)

* Correspondence: francesco.nobili@unicam.it; Tel.: +39-0737-402216

Received: 15 October 2020; Accepted: 23 November 2020; Published: 26 November 2020

\begin{abstract}
The reuse and recycling of products, leading to the utilization of wastes as key resources in a closed loop, is a great opportunity for the market in terms of added value and reduced environmental impact. In this context, producing carbonaceous anode materials starting from raw materials derived from food waste appears to be a possible approach to enhance the overall sustainability of the energy storage value chain, including Li-ion (LIBs) and Na-ion batteries (NIBs). In this framework, we show the behavior of anodes for LIBs and NIBs prepared with coffee ground-derived hard carbon as active material, combined with green binders such as Na-carboxymethyl cellulose (CMC), alginate (Alg), or polyacrylic acid (PAA). In order to evaluate the effect of the various binders on the charge/discharge performance, structural and electrochemical investigations are carried out. The electrochemical characterization reveals that the alginate-based anode, used for NIBs, delivers much enhanced charge/discharge performance and capacity retention. On the other hand, the use of the CMC-based electrode as LIBs anode delivers the best performance in terms of discharge capacity, while the PAA-based electrode shows enhanced cycling stability. As a result, the utilization of anode materials derived from an abundant food waste, in synergy with the use of green binders and formulations, appears to be a viable opportunity for the development of efficient and sustainable Li-ion and Na-ion batteries.
\end{abstract}

Keywords: sustainability; food waste-derived hard carbon; binder; Li-ion batteries; Na-ion batteries

\section{Introduction}

Ensuring access to affordable, reliable, sustainable, and modern energy for all is a massive challenge in modern society, facing the exponential industrial development, the population growth, and the depletion of fossil fuels [1]. Concerning electrochemical storage and conversion of energy, some of the most widespread practical technologies today include Li-ion batteries (LIBs), Na-ion batteries (NIBs) and supercapacitors [2,3]. Li-ion batteries are the most developed energy storage devices due to their high energy density, long cycle life, and light weight [4]. LIBs are often used in portable electronics such as computers or power tools, mobile devices, and, progressively, in electric vehicles and stationary battery storage systems $[5,6]$. Regardless of the rapid market growth for these electrical devices, lithium use is potentially limited by material shortages $[7,8]$. If it will prove unable to meet the high demand, lithium's leading role now may make room for Na-ion batteries, at least for less demanding applications. NIBs are commonly used in large-scale electrical energy storage [9]. Currently, NIBs have drawn significant attention as a potential alternative for LIBs, despite their lower 
performance, because of their lower cost and their similar electrochemical properties, as well as the higher abundance of sodium in nature (Earth's crust and oceans) [9-11].

Graphite is the standard anode material for LIBs. It provides theoretical capacity of $372 \mathrm{mAh} \mathrm{g}^{-1}$ [8], resulting in limitations in meeting the high-energy-devices market demands, such as those dictated by electrified vehicles. Regarding its utilization in NIBs, the possibility of storing Na in graphite is very limited, due to their larger ionic size and the low thermodynamic stability of the sodium-graphite intercalation compounds, resulting in poor electrochemical performance as anode material [12-15].

In order to overcome these limitations, significant effort has been made in the research related to hard carbons-nongraphitizable carbons-as advanced anode materials for both LIBs and NIBs, as a result of their similar electrochemical properties with graphite [16-20].

Hard carbon (HC) consists of single layers of carbon atoms that are arranged in a planar hexagonal network, but irregular and disordered along the c-axis [21-23]. Hard carbons that are produced from pyrolysis of polymers, combustion of saccharides, and biomass precursors are considered the most promising electrode materials due to their ability to provide high capacity and high-rate capability [2]. Besides the advantages, a large drawback of hard carbon use is its irreversible capacity because of the irreversible reactions occurring between the electrolyte and carbon groups followed by the decomposition of electrolyte and the formation of a solid electrolyte interphase (SEI) layer during the first insertion. This irreversible capacity is smaller in NIBs [23].

On the other hand, reusing and disposing waste materials are critical issues regarding environmental challenges [24]. Besides, a growth in population and the improvement of technology has led to an increased demand for energy, resulting in potential issues of raw materials availability. As a result, the use of alternative sources of carbonaceous materials seems to be a key challenge to improve the overall sustainability of LIB and NIB technology.

Food waste, such as coffee grounds, can be used as a great source of hard carbon due to its substantial availability worldwide, presenting high market potential as cheap raw material for LIBs and NIBs anode production.

Binders not only need to give high adhesion strength of the electrode film to the substrate, but also need to provide a good contact between the active materials and conductive carbon black [25-27]. Among the binders, poly(vinylidene difluoride) (PVDF) binder is extensively used in commercial batteries due to its sufficient binding strength and good electrochemical stability for both LIBs and NIBs [25,28-30]. However, PVDF requires the use of N-methyl-2-pyrrolidone (NMP) as a solvent during slurry preparation and casting. As a consequence, the major drawbacks of organic-based electrode sheets include the high cost, toxicity, and flammability $[25,28]$.

Beyond the economic and environmental perspective, another concern is the migration-controlled drying kinetics of PVDF binder, which is associated with the migration of PVDF to the surface due to the flow of NMP during the slow evaporation, which may affect adhesion, mechanical resistance, and charge/discharge efficiency [29]. Moreover, due to the likely formation of stable LiF and unsaturated $>\mathrm{C}=\mathrm{CF}$ - bonds at high temperatures, there are possibilities of exothermic reactions between the fluorine contained in PVDF and lithiated graphite or metal lithium, which may trigger thermal runaway of electrolyte and cell [26].

As alternative approaches, researchers have been investigating nontoxic, inexpensive, more easily processable, and high-drying-rate binders, such as Na-carboxymethyl cellulose (CMC), Na-alginate (Alg) and poly(acrylic acid) (PAA). These binders can be dissolved in water and can be easily disposed at the end of the battery life, so they are called green binders [25,29].

In this context, we show here the results of research about electrochemical performances of anodes based on a coffee ground-derived hard carbon (CGDHC) as active material, and CMC, alginate, PAA or PVDF as binders. Among the natural-derived binders, $\mathrm{CMC}$ is made by the insertion of carboxymethyl groups into natural cellulose [28], while alginate is made of natural polysaccharide extracted from brown algae [28]. Investigations about the use of PAA binder have also been carried out, because of the PAA ability to form strong hydrogen bonds with active materials and current collectors due 
to carboxylic acid functional groups [26], uniform distribution, proper swelling, and high binding ability [30].

As a consequence, anode materials for LIBs and NIBs prepared with food waste-derived hard carbon promise cost breakdown and environmentally benignity, and together with the use of aqueous binders enable considerable improvements of the overall sustainability of batteries (see Figure 1).

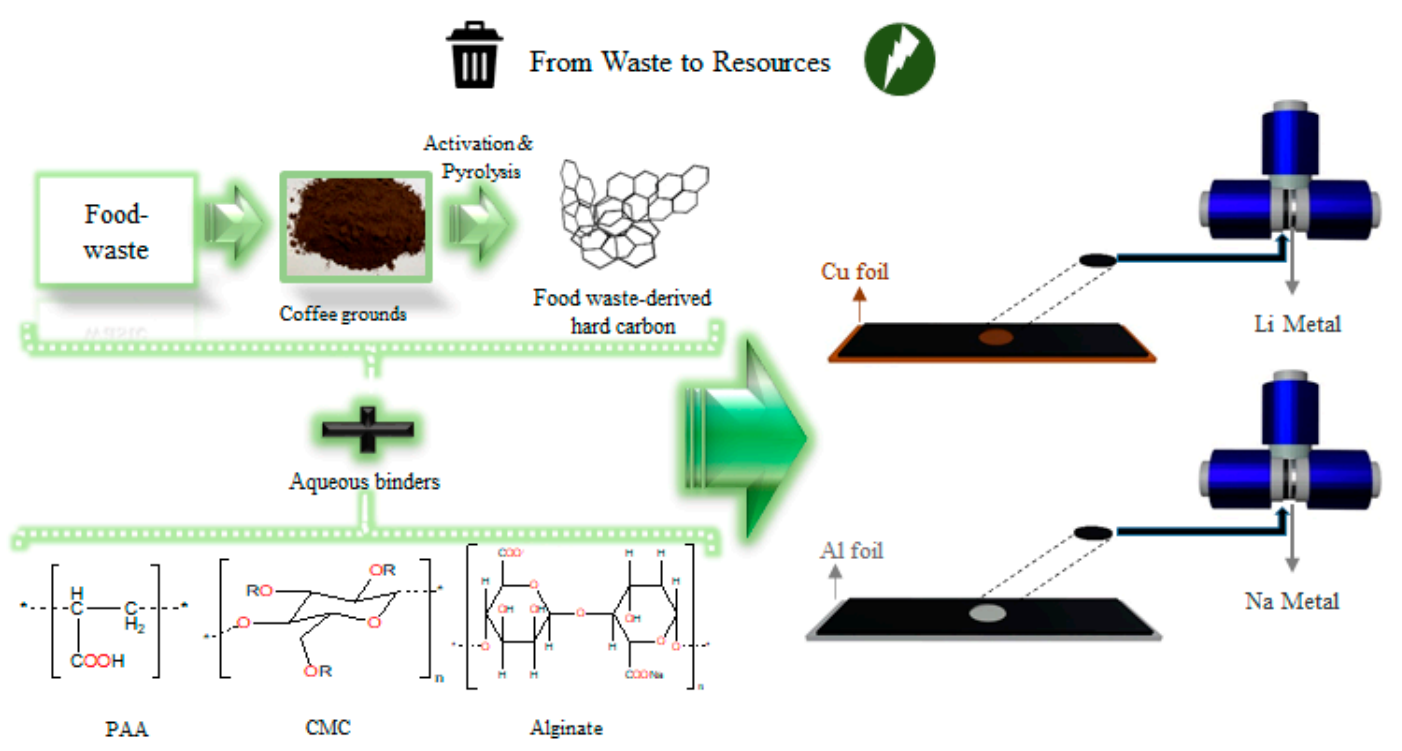

Figure 1. Procedure used to obtain cheap and environmentally friendly food waste-derived hard carbon anode materials and electrode processing with aqueous binders.

In this context, the focus of the current research is understanding the impact of binders on properties and behavior of electrodes based on hard carbon derived from coffee grounds, and especially the effects given by the different physical structures of the electrodes toward the electrochemical response in LIBs and NIBs.

\section{Experimental}

\subsection{Synthesis of Coffee Ground-Derived Hard Carbon}

Samples of hard carbon were synthesized through chemical acid activation of coffee grounds. The procedure adopted for preparing coffee grounds hard carbon (labeled as CGDHC) is as follows. Initially, coffee grounds were dried at $80^{\circ} \mathrm{C}$ for 3 days in an oven overnight for removing most of the water from the materials before use. Afterward, the dried powders were ground and treated with dilute hydrochloric acid $(\mathrm{HCl})$ solution for three days to improve the pore development in the carbon structure. Then, materials were washed with ultrapure water until around $\mathrm{pH} 7$ was eventually reached in the residual liquid, and were dried at $80{ }^{\circ} \mathrm{C}$ overnight. This was followed by pyrolysis of the obtained materials in a tubular furnace at $970{ }^{\circ} \mathrm{C}$ for $6 \mathrm{~h}$ under argon atmosphere after a heating ramp of $10{ }^{\circ} \mathrm{C} \mathrm{min}-1$, to obtain carbonized coffee grounds powder. During carbonization, small molecules, such as $\mathrm{H}_{2} \mathrm{O}, \mathrm{CO}_{2}$, and $\mathrm{N}_{2}$, among others, are released, resulting in high porosity materials with low particle density for a heat treatment temperature near $1000^{\circ} \mathrm{C}$ [21]. Finally, the obtained powder was ground in an automatic ball mill for $4 \mathrm{~h}$ to yield the CGDHC active material (agate jar of $50 \mathrm{~mL}$ and agate ball diameter $10 \mathrm{~mm}$, ball-to-powder weight ratio of 4:1).

\subsection{Material Characterization}

X-ray diffraction technique was used to investigate the crystal structure of the prepared materials (Bragg-Brentano geometry, $\mathrm{Cu}-\mathrm{K} \alpha, \lambda=1.54059 \AA$ ). . The morphologies of the powder and the electrodes 
with different binders were captured using scanning electron microscopy (a FESEM Cambridge Stereoscan 360 electron microscope). Raman spectra were performed for the CGDHC powder and the electrodes, before and after a $12 \mathrm{~h}$ OCV period, using a Horiba IHR 320, wavelength $532 \mathrm{~nm}$. Pore characteristics of the CGDHC materials were investigated by $\mathrm{N}_{2}$ adsorption/desorption isotherms at $-195.8^{\circ} \mathrm{C}$ using a Micromeritics ASAP 2020 instrument. Prior to the adsorption/desorption measurement, the CGDHC sample had been outgassed for $12 \mathrm{~h}$ at $30{ }^{\circ} \mathrm{C}$. The specific surface area and pore size distribution values were calculated by the linear plot in the relative pressure range and the density function theory (DFT), respectively.

\subsection{Electrodes Preparation and Cell Assembling}

Various electrodes were prepared by mixing $80 \%$ of active material with $10 \%$ of conductive carbon C65 and 10\% of different binders, including CMC, alginate, PAA, and PVDF binders. The slurries were casted onto aluminum foil for NIBs and onto copper for LIBs by using a doctor blade to acquire a homogenous thickness film. The solvents used for CMC, PAA, alginate, and PVDF binders were water, ethanol (due to faster drying and better performances), water, and $N$ - methylpyrrolidone (NMP), respectively. After drying the coatings, the electrodes were cut and dried again under vacuum at $120^{\circ} \mathrm{C}$ overnight to evaporate solvent residues and to yield the electrode layers. Cells were assembled in a glove box (Jacomex GP-campus, oxygen and moisture content less than $0.8 \mathrm{ppm}$ ) using T-shape polypropylene Swagelok-type 3 cells. Lithium metal (Sigma-Aldrich) was used as the counter and reference electrodes for LIBs and sodium metal (Alfa-Aesar) were used as the counter and reference for NIBs. For all cells, a glass fiber disk (Whatman GF/A) was used as separator, while $1 \mathrm{M} \mathrm{LiPF}_{6}$ in ethylene carbonate (EC):dimethyl carbonate (DMC) 1:1 v/v (preformulated by Solvionic, France) and $1 \mathrm{M} \mathrm{NaClO}_{4}$ (Sigma-Aldrich) in EC:PC (Sigma-Aldrich) 1:1 v/v were used as electrolytes $(400 \mu \mathrm{L})$ for LIBs and NIBS, respectively. After assembly, the cells were removed from the glove box for electrochemical characterization.

\subsection{Electrochemical Characterization}

All electrochemical tests were carried out using a VMP-2Z multichannel electrochemical workstation by Bio-Logic (France). Cyclic voltammetry of the samples for LIBs and NIBs were carried out at a scanning rate of $0.05 \mathrm{mV} / \mathrm{s}$ in the voltage between 0.02 to $2.2 \mathrm{~V}$ to assess the topotactical reaction of Li for LIBs and of Na for NIBs in the synthetized materials. Galvanostatic charge/discharge tests of the electrodes were collected with the voltage ranging between from 0.02 and $2.2 \mathrm{~V}$. All voltages are given vs. $\mathrm{Li}^{+} / \mathrm{Li}$ and $\mathrm{Na}^{+} / \mathrm{Na}$ couples for LIBs and NIBs, respectively. For both LIBs and NIBs, 1C rate was assumed as $300 \mathrm{~mA} / \mathrm{g}$ with respect to active material mass. In order to evaluate the interfacial behavior of electrodes, electrochemical impedance spectroscopy was carried out at each tenth cycle at $\mathrm{E}=0.5 \mathrm{~V}$.

\section{Result and Discussion}

\subsection{Chemical, Structural, and Morphological Characterization of the Material}

Chemical, structural, and morphological characteristic of pristine coffee grounds was carried out. Scanning electron microscopy (Figure S1a) reveals pores at the micrometer scale. Elemental analysis, carried out on pristine and final powders, reveals (Figure S1b,c) the presence of minor amounts of nitrogen in both samples, which can enhance conductivity of the sample. The presence of $\mathrm{N}$ is also evidenced in FTIR analysis (Figure S1d) of the pristine coffee grounds, while after the high-T thermal treatment, a flat signal typical of a conductive carbon material is observed.

According to XRD patterns of graphite and soft and hard carbon reported in the literature, the level of structure disorder and the interlayer distances increase from soft to hard carbon [22]. Figure 2a illustrates the X-ray diffraction patterns of the CGDHC synthesized according to the procedure reported in the Experimental and calcinated at $\mathrm{T}=970{ }^{\circ} \mathrm{C}$ for $6 \mathrm{~h}$. The XRD diffraction pattern exhibits very 
broad features, referring to (002) and (100) planes of hard carbon, at $2 \theta$ around $23^{\circ}$ and $43^{\circ}[8,14]$. No impurity-related peaks are observed from the XRD patterns, which indicate the absence of other phases. The interlayer spacing $d_{002}$ and the stacking height $L_{c}$ were obtained by following Equations (1) (Bragg's law) and (2) (Scherrer), respectively [23,31]:

$$
d_{002}=\lambda / 2 \sin \left(\theta_{002}\right)
$$

where $\lambda=0.154 \mathrm{~nm}$ and

$$
L_{c}=0.9 \lambda / \beta_{002} \cos \left(\theta_{002}\right)
$$

where $\beta_{002}$ is equal to one-half of the width of the 002 peak.
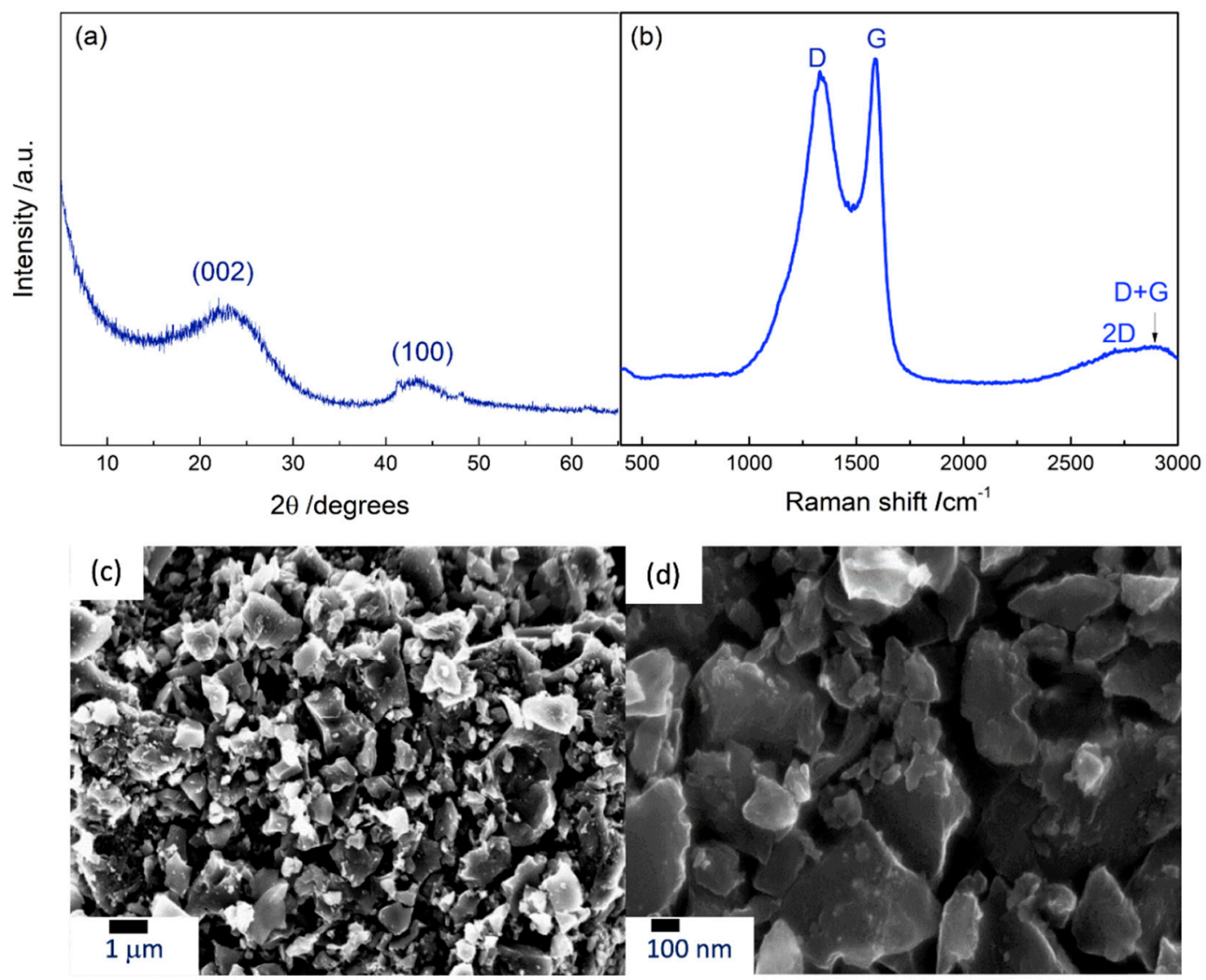

Figure 2. Structural and morphological investigation of the CGDHC powder. (a) XRD pattern. (b) Raman spectrum. SEM images of coffee ground-derived hard carbon (CGDHC) powder at a magnification of $10 \mathrm{kX}(\mathbf{c})$ and $40 \mathrm{kX}(\mathbf{d})$.

Additionally, the number $n$ of graphene stacking layers was determined by dividing $L_{c}$ by $d_{002}$ [23]. The results are presented in Table 1. Notably, the interlayer spacing of the CGDHC powder is calculated to be $0.386 \mathrm{~nm}$, which is higher than that of graphite $(0.335 \mathrm{~nm})$, facilitating $\mathrm{Na}^{+}$ion insertion/extraction between carbon layers [32].

Table 1. Crystallographic parameters calculated by XRD and Raman data analysis.

\begin{tabular}{cccccc}
\hline Sample & $d_{002}$ & $\boldsymbol{L}_{\boldsymbol{c}}(\mathrm{nm})$ & $\boldsymbol{n}$ & $\boldsymbol{I}_{\boldsymbol{D}} / \boldsymbol{I}_{G}$ & $\boldsymbol{L}_{\boldsymbol{a}}(\mathrm{nm})$ \\
\hline CGDHC-Powder & 0.386 & 0.732 & 1.89 & 0.965 & 19.92 \\
\hline
\end{tabular}


The Raman spectrum of CGDHC powder, shown in Figure $2 b$, indicates two sharp and intense peaks of D-band at $\sim 1330.12 \mathrm{~cm}^{-1}$ and of G-band at $\sim 1586.77 \mathrm{~cm}^{-1}$. The D-band "the defect-induced band" is correlated with vacancies or the attendance of functional groups, whereas the G-band "the crystalline graphite" corresponds to the graphitic vibrations $[8,31]$. The intensity ratio $I_{D} / I_{G}$ value describes the ratio between the degree of defects and the degree of graphitization. For CGDHC it is calculated as 0.965 , suggesting a relatively high-graphitization degree of hard carbon [8]. Moreover, two broad peaks are located at around 2600 and $2950 \mathrm{~cm}^{-1}$, which correspond to $2 \mathrm{D}$ and D+G bands. The $2 \mathrm{D}$ band is associated with the degree of graphitization and the $D+G$ band is associated with defect activated process for an elastic scattering [31]. The graphitic domain size of hard carbon sample was also independently calculated from $[20,23]$ :

$$
L_{a}=\left(2.4 \times 10^{-10}\right) \lambda^{4}\left(I_{D} / I_{G}\right)^{-1}
$$

where $L_{a}$ is the graphitic domain size (nm) and $\lambda$ is $532 \mathrm{~nm}$ (shown in Table 1).

The crystallographic parameters were calculated using the equations and the results can be found in Table 1, indicating a certain degree of graphitization besides a disordered structure of CGDHC hard carbon powder [23,31]. As it can be seen in Figure 2c,d, the SEM images of the CGDHC powder show block morphology and fine fragments. It can be mentioned that the particle size is nonuniformly distributed.

Heat treatment under high argon flow plays a critical role in enhancing specific surface area and in creating porosity by flushing away the released gases. Not only pyrolysis, but also acid treatment has a considerable effect on enhancing porosity [21]. The $\mathrm{N}_{2}$ adsorption/desorption isotherms were used to study the porosity of CGDHC powder and the results are presented in Figure S2. The calculated Brunauer-Emmett-Teller (BET) surface area, pore diameter (DFT theory), Barrett-Joyner-Halenda $(\mathrm{BJH})$ adsorption average pore diameter, and cumulative surface area of pores are $787.26 \mathrm{~m}^{2} / \mathrm{g}, 1.02 \mathrm{~nm}$, $4.6 \mathrm{~nm}$, and $541.01 \mathrm{~m}^{2} / \mathrm{g}$, respectively. The high BET specific surface area and pore size distribution of CGDHC material can provide good electrolyte ion accessibility to carbon layers, resulting in good electrochemical performance [8].

\subsection{Structural and Morphological Characterization of the Electrodes}

In order to get information about possible modifications of the hard carbon layers arrangement induced by the different binders used for electrodes formulation, Raman spectra was performed on the CGDHC-based electrodes prepared with CMC, Alg, PAA, and PVDF binders, respectively labeled as CGDHC-CMC, CGDHC-Alg, CGDHC-PAA, and CGDHC-PVDF. This information can be obtained by calculating the ratio between the $\mathrm{I}_{\mathrm{D}}$ and $\mathrm{I}_{\mathrm{G}}$ bands. The comparison of Raman spectra of electrodes with different binders for LIBs and NIBs is shown in Figure S3, while the calculated $I_{D} / I_{G}$ and $\mathrm{L}_{a}$ are presented in Table S1. As expected, all the Raman spectra present the same characteristic peaks already observed for the powder at $\sim 1345 \mathrm{~cm}^{-1}$ (D-band) and $\sim 1590 \mathrm{~cm}^{-1}$ (G-band) [8], together with two broad peaks in the range of $2650-2950 \mathrm{~cm}^{-1}$, correlated to $2 \mathrm{D}$ and $\mathrm{D}+\mathrm{G}$ bands [31]. Commonly, the graphitization degree of hard carbon is bound to conductivity [23], while porosity and defects enable surface storage processes (thus relevant for NIBs) [33]. However, in the present case the data provide evidence, for all electrodes, of similar peak shapes and only small variations of the intensity ratio between $D$ and $G$ bands. This behavior may be attributed to only minor interactions of the active CGDHC and of the conductive additive with the functional groups. Therefore, we may exclude a relevant role of the binder in modifying structural or conduction properties of the active materials.

On the contrary, the different binders are expected to play a key role in modifying aggregation and morphology of the electrodes, as demonstrated by SEM images of CGDHC-CMC, CGDHC-Alg, CGDHC-PAA, and CGDHC-PVDF electrodes, both for LIBs and NIBs. Figures 3 and 4 show the surface morphology of the prepared electrodes for LIBs and NIBs, respectively. Two magnification levels (1 and $40 \mathrm{kX}$ ) are shown. Among the electrodes prepared for LIBs (Figure 3), CGDHC-CMC shows a 
more homogenous particle distribution and lower aggregation at both higher and lower magnifications (panels $a$ and b), with no evidence of cracking. For alginate- and PAA-based electrodes (panels $\mathrm{c}$ and $\mathrm{d}$, and e and $\mathrm{f}$, respectively), it appears that more particles are agglomerated and connected with neighboring ones, tending to form more clusters. SEM images of CGDHC-PVDF electrode surface for LIBs display some obvious intergranular and microcracks, as highlighted by arrows (panels $\mathrm{g}$ and h). These results suggest that during the drying process the PVDF-based electrode becomes brittle, and eventually cracks keep growing on the surface of the electrode after pressing. It is speculated that the existence of cracks may result in poor contact between particles and between particles and current collectors [34]. Additionally, these cracks that form can expose further interfacial area to side reactions and gradually lose active materials, potentially leading to inferior electrochemical performances in the long run.

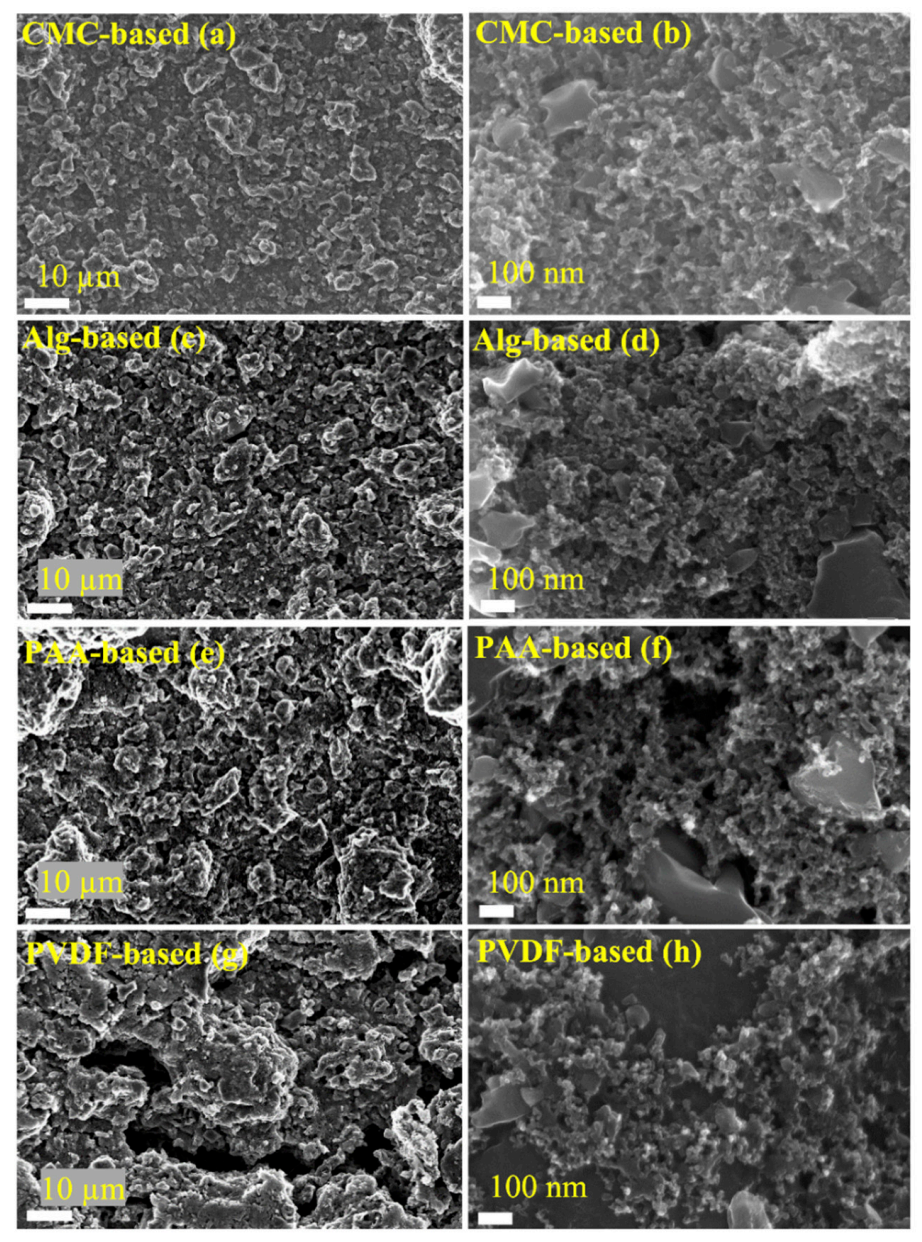

Figure 3. SEM images of the surface of the CGDHC-based lithium-ion battery (LIB) electrodes prepared with different binders at different magnifications. (a,b) Na-carboxymethyl cellulose (CMC) binder; (c,d) alginate (Alg) binder; (e,f) polyacrylic acid (PAA) binder; (g,h) poly(vinylidene difluoride) (PVDF) binder. 


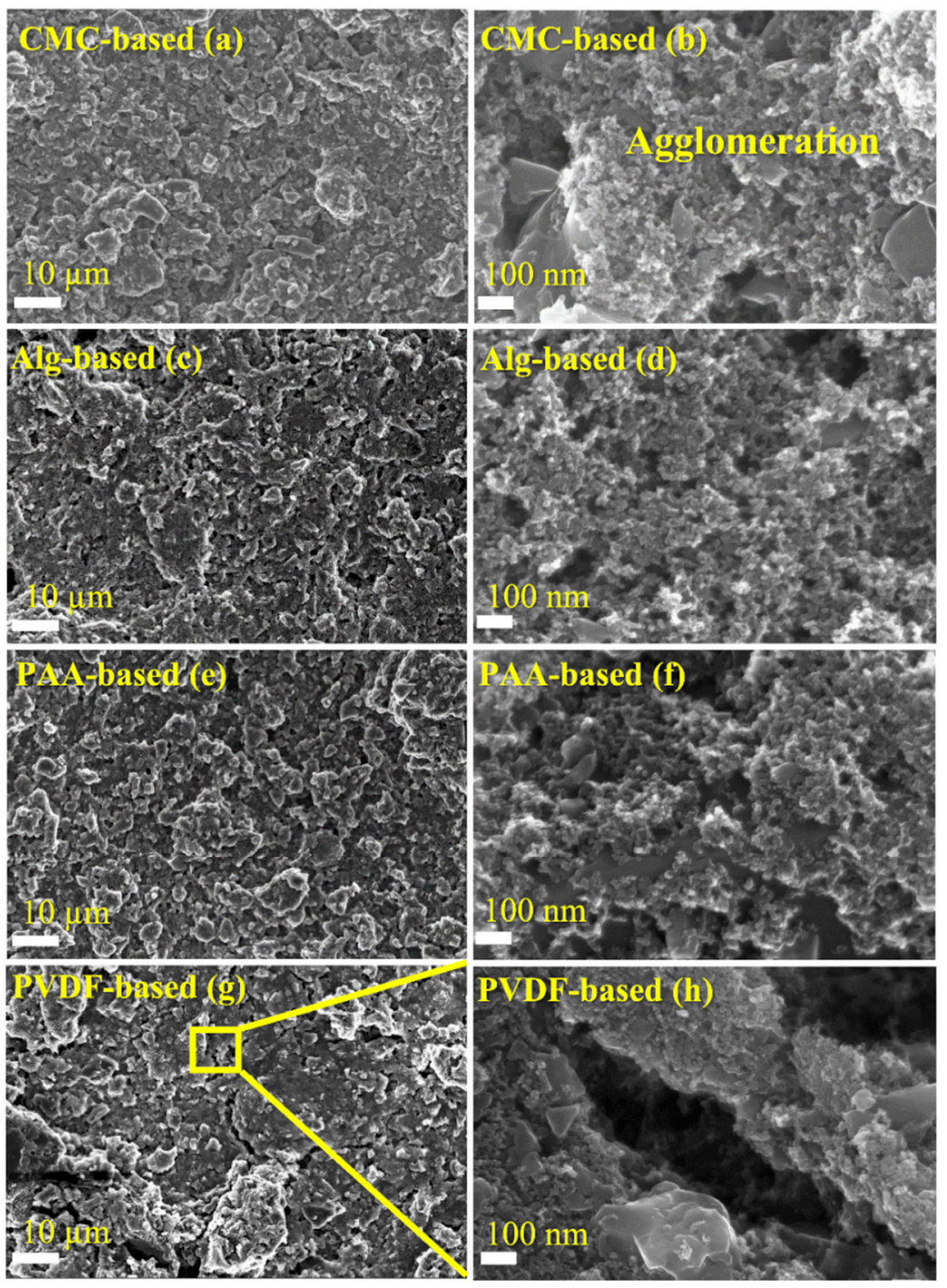

Figure 4. SEM images of the surface of the CGDHC-based Na-ion battery (NIB) electrodes prepared with different binders at different magnifications. (a,b) Na-carboxymethyl cellulose (CMC) binder; (c,d) alginate (Alg) binder; (e,f) polyacrylic acid (PAA) binder; (g,h) poly(vinylidene difluoride) (PVDF) binder.

SEM images of the electrode prepared for NIBs (Figure 4) show a very similar trend, with only minor improvements for the alginate-based electrode, which in this case shows a lower degree of agglomeration (panels $\mathrm{c}$ and d). For NIBs, the formation of clusters and aggregation of particles are critically important and can be considered as an essential disadvantage due to the need of keeping a large interfacial area exposed to electrolyte upon charge/discharge processes in order to exploit the surface storage mechanisms [35]. As for the corresponding LIB anodes, some microcracks can be also found on the surface of PVDF-based electrode for NIBs, additionally in this case because of the brittle nature of the pressed CGDHC-PVDF film.

\subsection{Electrochemical Behavior}

In order to investigate the reaction processes taking place during the reversible Li storage and investigating the impact of the different binders on the charge/discharge performance, all electrodes underwent cyclic voltammetry $(\mathrm{CV})$ at a scan rate of $0.05 \mathrm{mV} / \mathrm{s}$, and galvanostatic cycles in the potential window of $0.02-2.20 \mathrm{~V}$ in half-cells vs. Li and $\mathrm{Na}$. The voltammograms acquired during the first and 
second cycles vs. Li are shown in Figure 5. For all electrodes, a large peak with an onset potential around $0.75 \mathrm{~V}$ is seen during the first cathodic scan, reflecting the first-cycle irreversible reactions of electrolyte with electrode surface [30]. This peak is due to electrolyte decomposition and formation of the surface protection layer known as solid electrolyte interphase (SEI), which results in irreversible capacity $[8,30]$. This peak is not evidenced during the following cycles, suggesting that most of the irreversible interfacial processes were completed during the first discharge. The peak is superimposed to a large, reversible, flat profile, which reflects the reversible nature of Li surface storage by amorphous carbon. At low potentials, all samples show a main, reversible peak with an onset potential around $0.1 \mathrm{~V}$, highlighting intercalation of $\mathrm{Li}^{+}$ions between carbon layers; this peak is maintained during the subsequent scans, confirming the reversible nature of the Li intercalation. During the anodic scan, the CVs of all samples confirm the reversibility of the low-potential peak around $0.1 \mathrm{~V}$, bound to $\mathrm{Li}$ deintercalation from carbon layers, and of the flat area extending up to higher potentials, bound to $\mathrm{Li}$ storage at the carbon surface [36].

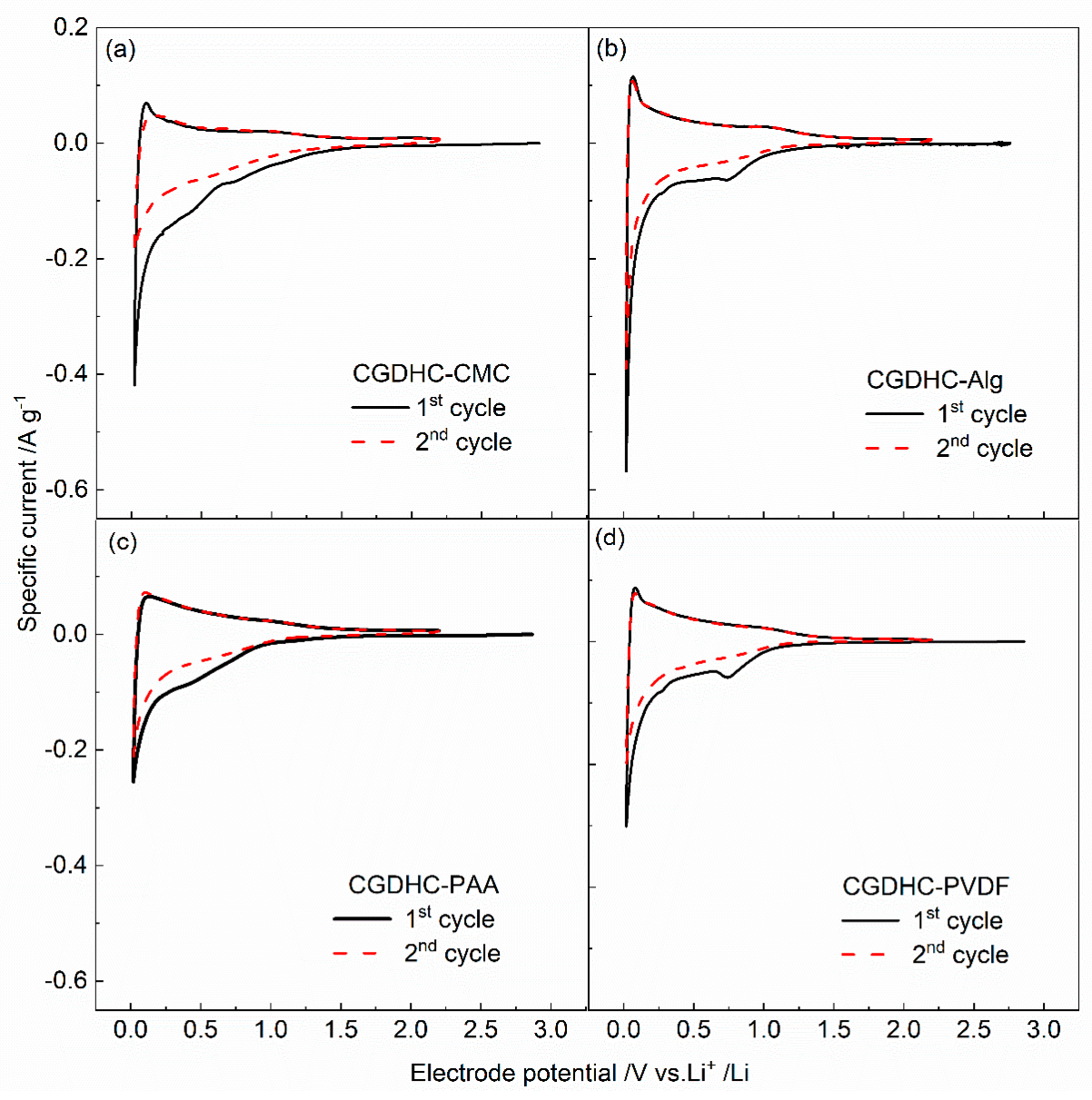

Figure 5. CV profiles, acquired during the first and second cycles, of CGDHC-based LIB electrodes prepared with different binders: (a) Na-carboxymethyl cellulose (CMC); (b) alginate (Alg); (c) polyacrylic acid (PAA); (d) poly(vinylidene difluoride) (PVDF). Scan rate $0.05 \mathrm{mV} \mathrm{s}^{-1}$.

Figure 6 shows the galvanostatic charge/discharge E vs. Q profiles of the CGDHC electrodes prepared with different binders in Li half-cells. During the first cycle, all electrodes evidence a capacity on the order of $600-700 \mathrm{mAh} \mathrm{g}^{-1}$ and the corresponding coulombic efficiencies of around $56 \%$. These values include a large contribution from irreversible capacity, which can be related to the high specific surface area of the hard carbon material, resulting in massive decomposition of electrolyte at the carbon surface and formation of the SEI layer [8,36-38]. The galvanostatic profiles confirm that this 
process starts at around $0.80 \mathrm{~V}$ and carries on until about $0.20 \mathrm{~V}$, where it is overlapped by a broad profile related to reversible $\mathrm{Li}^{+}$ion intercalation and storage at the nanopore surface [36]. These results compare well with the features evidenced by the CV profiles.

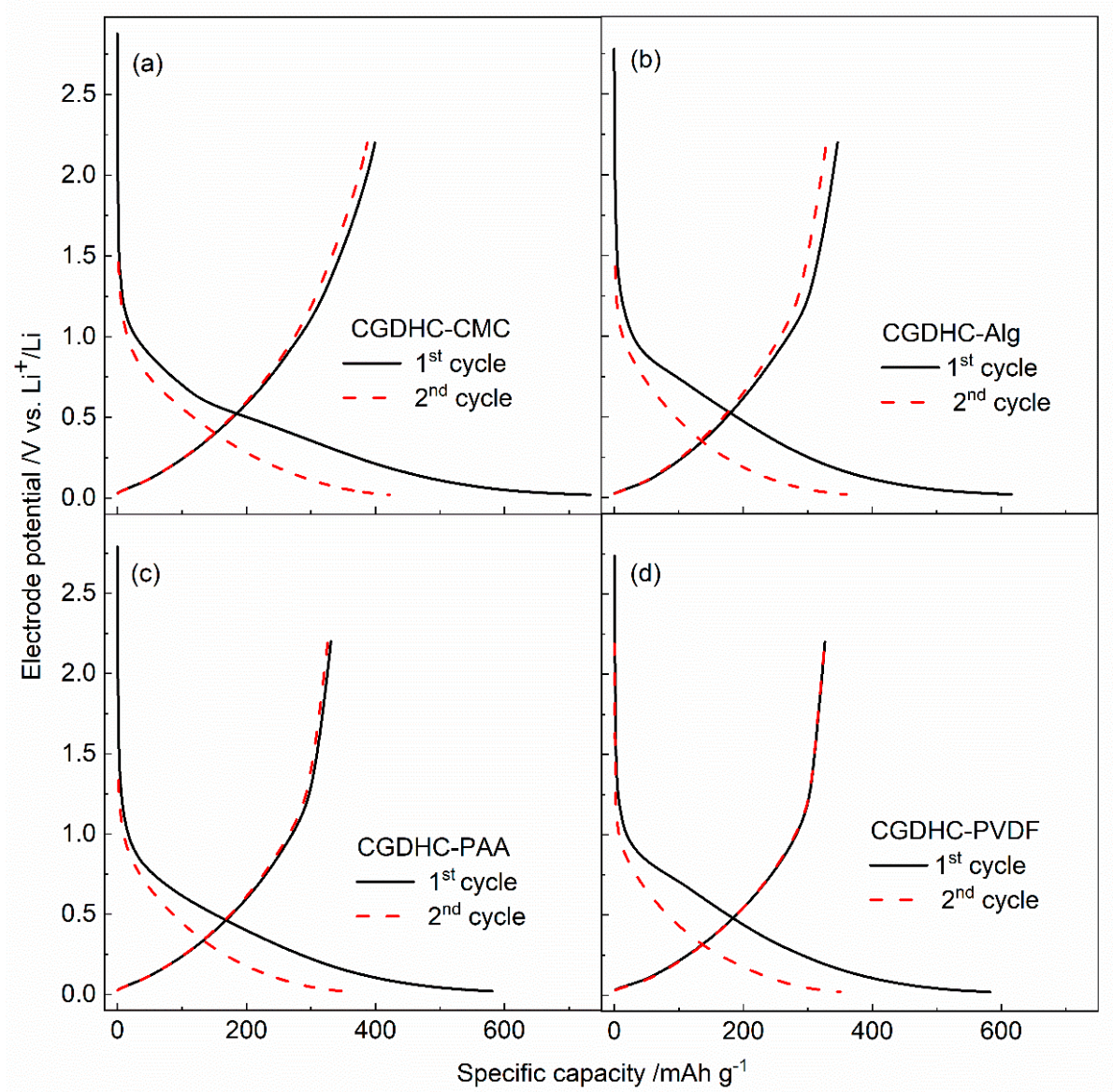

Figure 6. E vs. Q galvanostatic profiles, acquired during the first and second cycles, of CGDHC-based LIB electrodes prepared with different binders: (a) Na-carboxymethyl cellulose (CMC); (b) alginate (Alg); (c) polyacrylic acid (PAA); (d) poly(vinylidene difluoride) (PVDF). Cycling rate C/5.

During the second cycle, the discharge capacity of CGDHC-CMC is $421.86 \mathrm{mAh} \mathrm{g}^{-1}$ at $0.2 \mathrm{C}$, while lower values of $360.19,350.37$, and $350.17 \mathrm{mAh} \mathrm{g}^{-1}$ are obtained for CGDHC-Alg, CGDHC-PAA, and CGDHC-PVDF, respectively. According to these results, the enhanced capacity of an electrode using CMC for LIBs can be attributed to improved mechanical and interfacial properties and uniform electrode morphology [29]. In fact, the highest capacity could be assumed to the more homogeneous distribution of conductive carbon and CMC binder between active materials, resulting in enhanced interparticle electrical contact, as reported by Wang et al. for graphite LIBs electrodes [29,39]. The electrode prepared with alginate binder also delivers capacity improvement with respect to those prepared with PAA or PVDF. This result confirms the hypothesis that PVDF-based electrodes can be affected by poor electrochemical properties, with respect to other binders, due to migration-controlled drying kinetics [29], exothermic reactions as mentioned in the introduction [26,40], desquamation of electrode particles (fall-off from copper foil) [25], cracking of the electrode as shown in SEM, and low flexibility, which leads to breaking the contact between active materials and conductive carbon upon cycling [26,41].

Figure 7a displays the discharge capacity values obtained by cycling at C/5-rate in Li-ion half-cells the CGDHC electrodes prepared using the different binders. Some differences are revealed in terms of capacity values and capacity retention. At C/5, the CMC-based electrode shows higher capacity 
values through all over the investigated cycles in both conditions, because of a homogenous coating on the copper electrode. The capacity values for alginate- and PAA-based electrodes are initially lower, but they then exhibit better capacity retention, while the PVDF-based electrode shows slightly lower capacities. In order to further evaluate the effects of binders for LIBs, the capacity retention also were evaluated at $2 \mathrm{C}$ for 500 cycles as shown in Figure $7 \mathrm{~b}$, where the differences become even more marked, with the highest capacity values obtained by the CMC-based electrode and the lowest values by the PVDF-based one. However, the PAA-based anode is able to retain performances upon long cycling. This could be related to appropriate mechanical properties of the PAA-based electrode [26], a more desirable conformation of polymer in the composite, and a more effective and stable SEI layer formation in fewer cycles, thus hindering agglomeration of polymer by electrostatic repulsion $[29,42]$. It is noteworthy that among different binders in LIBs, PAA also can form strong hydrogen bonds with active materials and substrate due to its chemical structure (carboxylic acid moieties interacting with polar groups at the edges of carbon planes) [26].

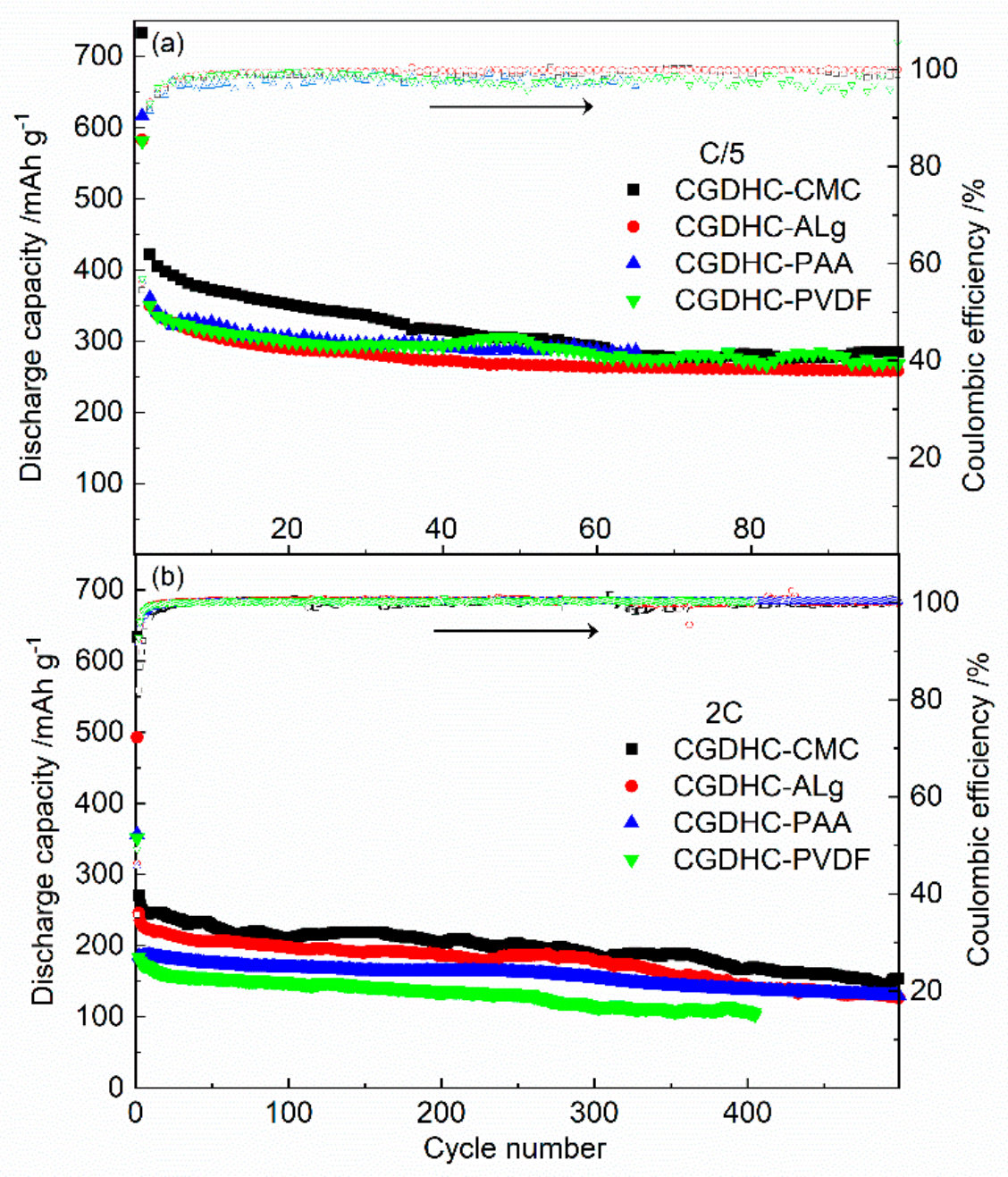

Figure 7. Cycle performance of CGDHC-based LIB electrodes with different binders. Cycling rate C/5 (a) and $2 \mathrm{C}(\mathbf{b})$.

In order to clarify the interfacial behavior of electrodes based on different binders, electrochemical impedance spectroscopy (EIS) was carried out every tenth cycle at E $=0.50 \mathrm{~V}$, confirming the reasons why changing binders can considerably improve the electrochemical performances. Figure 8a-d demonstrates the Nyquist plots recorded using different binders. All impedance dispersions show similar features: (i) a semicircle at high frequencies related to migration through passivation layer, 
which is partly overlapped by (ii) a semicircle at middle frequencies related to interfacial charge-transfer process; (iii) a sloped line at low frequencies associated with $\mathrm{Li}^{+}$ion diffusion in the bulk of the active materials [43]. EIS data were fitted using the equivalent circuit noted as $R_{e l}\left(R_{S E I} C_{S E I}\right)\left(R_{c t} C_{d l}\right) W C_{i}$ in the notation of Boukamp. $R_{\mathrm{el}}, \mathrm{R}_{\mathrm{SEI}}$, and $\mathrm{R}_{\mathrm{ct}}$ are associated with the resistances of electrolyte, of SEI film, and of the charge-transfer process, while $\mathrm{C}_{\mathrm{SEI}}, \mathrm{C}_{\mathrm{dl}}$, and $\mathrm{C}_{\mathrm{i}}$ are the capacitances related to passivation layer, electric double layer, and differential intercalation, respectively. $\mathrm{W}$ is the Warburg impedance, describing $\mathrm{Li}^{+}$ion diffusion [44]. The calculated values of $\mathrm{R}_{\mathrm{SEI}}$ and $\mathrm{R}_{\mathrm{ct}}$ are reported in Figure $\mathrm{S} 4$. The CMC-based electrode shows the lowest $R_{\mathrm{ct}}$ values, thus revealing improved kinetics and enhanced stability of its interfacial behavior. For the PVDF-based electrode, the high initial values of $R_{\mathrm{ct}}$ and the subsequent contraction may be explained by rearrangements of the electrode/electrolyte interface due to initial morphological instability.

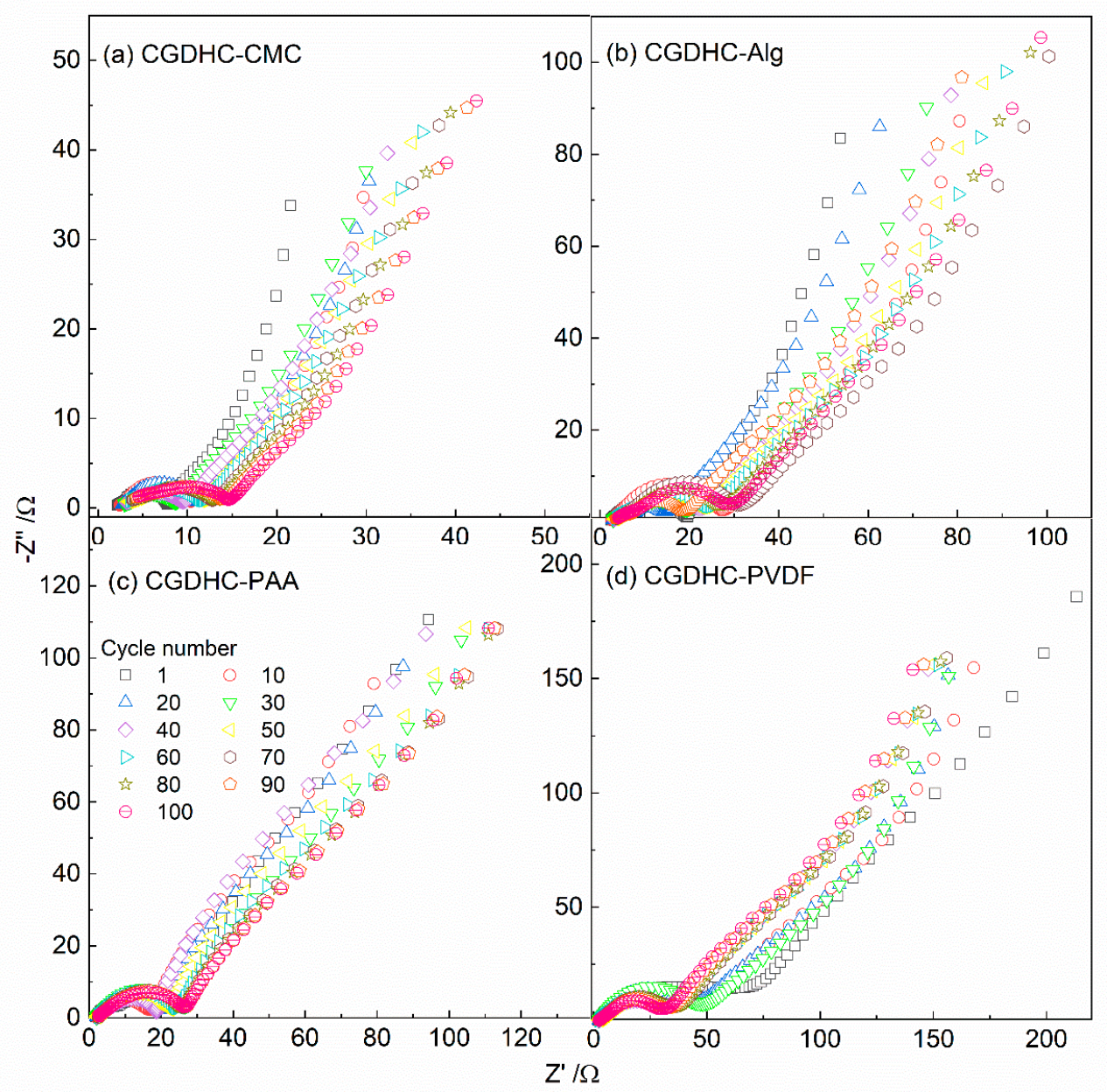

Figure 8. Nyquist plot of CGDHC-based LIB electrodes prepared with different binders: (a) Na-carboxymethyl cellulose (CMC); (b) alginate (Alg); (c) polyacrylic acid (PAA); (d) poly(vinylidene difluoride) (PVDF). $\mathrm{E}=0.50 \mathrm{~V} ; 10 \mathrm{mHz}<\mathrm{f}<100 \mathrm{kHz}$.

The charge/discharge behavior of CGDHC-based electrodes was investigated in Na half-cells as well, by performing cyclic voltammetry and galvanostatic cycles. The first- and second-cycle voltammograms vs. Na are presented in Figure 9 for all electrodes with different binders (CGDHC-CMC, CGDHC-Alg, CGDHC-PAA, and CGDHC-PVDF) in the potential range 0.02 to $2.20 \mathrm{~V}$. Similar to what was evidenced for LIBs, all electrodes show large peaks around or below $0.60 \mathrm{~V}$, which can be attributed to the reactions between electrolyte and surface functional groups, and the peak bringing to electrolyte decomposition and SEI formation [30]. However, it should be noted that (i) the sloping baselines starting around $0.60 \mathrm{~V}$ are more pronounced than for the corresponding LIB electrodes, and (ii) some 
differences arise among the different electrodes. In fact, the CMC- and PVDF-based electrodes show two features around 0.90 and $0.60 \mathrm{~V}$, respectively, while the Alg-based electrode shows a single evident feature around $0.50 \mathrm{~V}$. The PAA-based electrode shows only a less pronounced shoulder around $0.6 \mathrm{~V}$, mostly overlapped by the sloping baseline. These behaviors can be tentatively attributed to (i) more pronounced surface storage of $\mathrm{Na}$ than $\mathrm{Li}$, which extends over a broad potential window below $1 \mathrm{~V}$, and (ii) interfacial SEI formation processes that are partly modified by the different binders (possibly due to the higher surface reactivity and instability commonly found for NIBs with respect to LIBs) $[45,46]$. The redox peaks occurring close to the 0.02 cutoff potential in all electrodes can be explained by minor Na storage at the edges of carbon layers, or Na plating at the hard carbon surface (bulk intercalation is not allowed). During the following charges and discharges, only reversible processes occurring in a very broad potential range between 0.02 and $1.50 \mathrm{~V}$ are evidenced, signature of the reversible surface storage of Na by amorphous carbon.

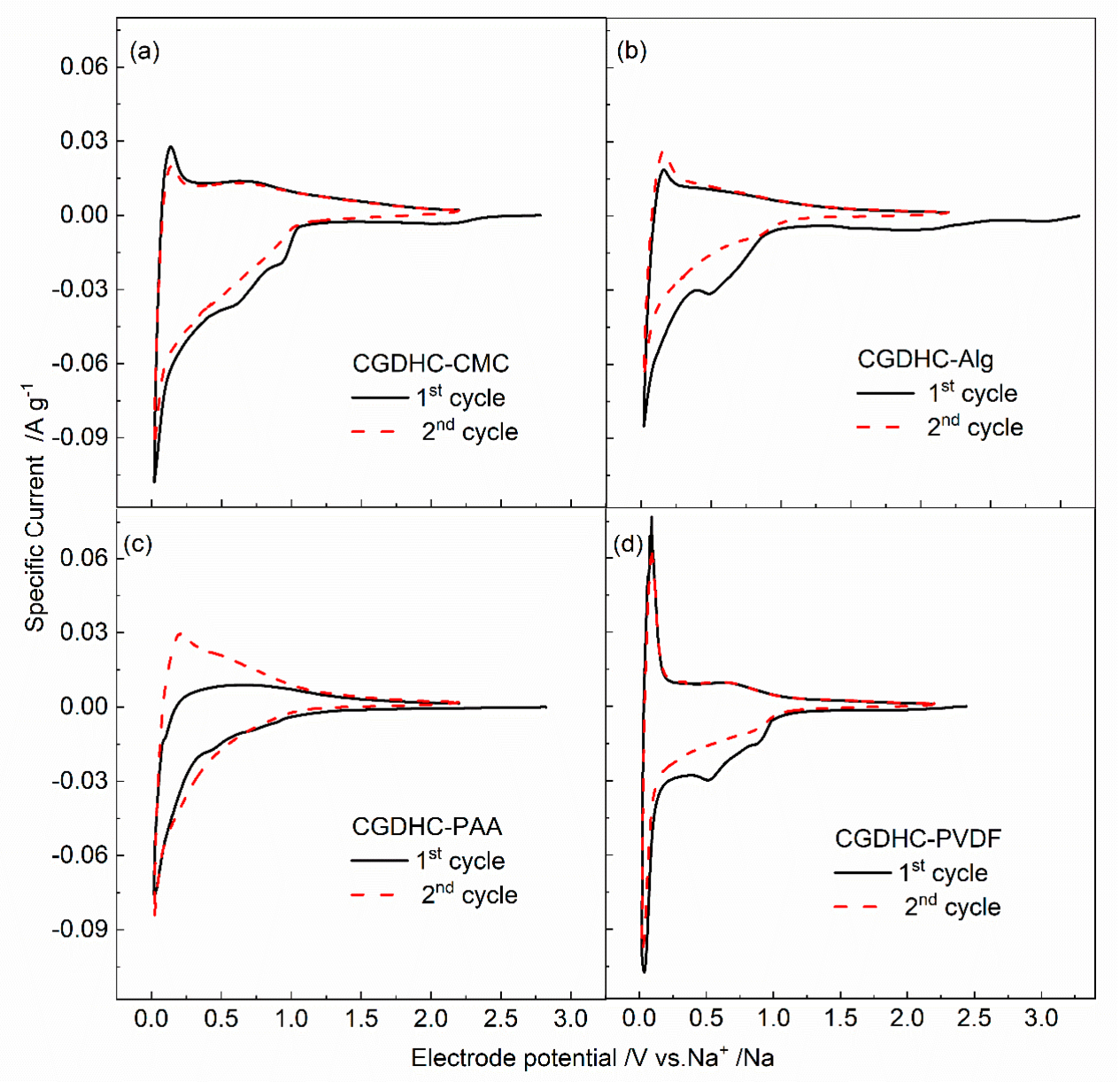

Figure 9. CV profiles, acquired during the first and second cycles, of CGDHC-based NIB electrodes prepared with different binders: (a) Na-carboxymethyl cellulose (CMC); (b) alginate (Alg); (c) polyacrylic acid (PAA); (d) poly(vinylidene difluoride) (PVDF). Scan rate $0.05 \mathrm{mV} \mathrm{s}^{-1 .}$

These results confirm that the electrochemical behavior of NIBs is similar to that of LIBs. Nevertheless, in addition to the inability to store $\mathrm{Na}^{+}$ions by intercalation, two further issues may arise: (1) the utilization of aluminum as current collector on the anode that is in contrast with LIBs, leading to $\mathrm{Al}$ corrosion, and (2) more pronounced sensitivity to water traces [47]. Therefore, selecting an appropriate binder can play a vital role in NIBs in terms of maintaining mechanical adhesion, keeping ionic contact, and facilitating the formation of a stable interface with the electrolyte [30]. 
Figure 10 shows the galvanostatic charge/discharge $\mathrm{E}$ vs. Q profiles of all electrodes during the first and second cycles. The CGDHC-Alg, CGDHC-PAA, CGDHC-CMC, and CGDHC-PVDF at C/5 in the voltage range between 0.02 and $2.2 \mathrm{~V}$ for NIBs in initial cycle deliver discharge capacity (including reversible and irreversible processes) of $250.44,263.38,335.52$, and $221.33 \mathrm{mAh} \mathrm{g}^{-1}$, respectively. During the second cycle, the CGDHC-Alg, CGDHC-PAA, CGDHC-CMC, and CGDHC-PVDF exhibit reversible discharge capacity of $173.51,164.84,152.62$, and $115.97 \mathrm{mAh} \mathrm{g}^{-1}$, respectively.

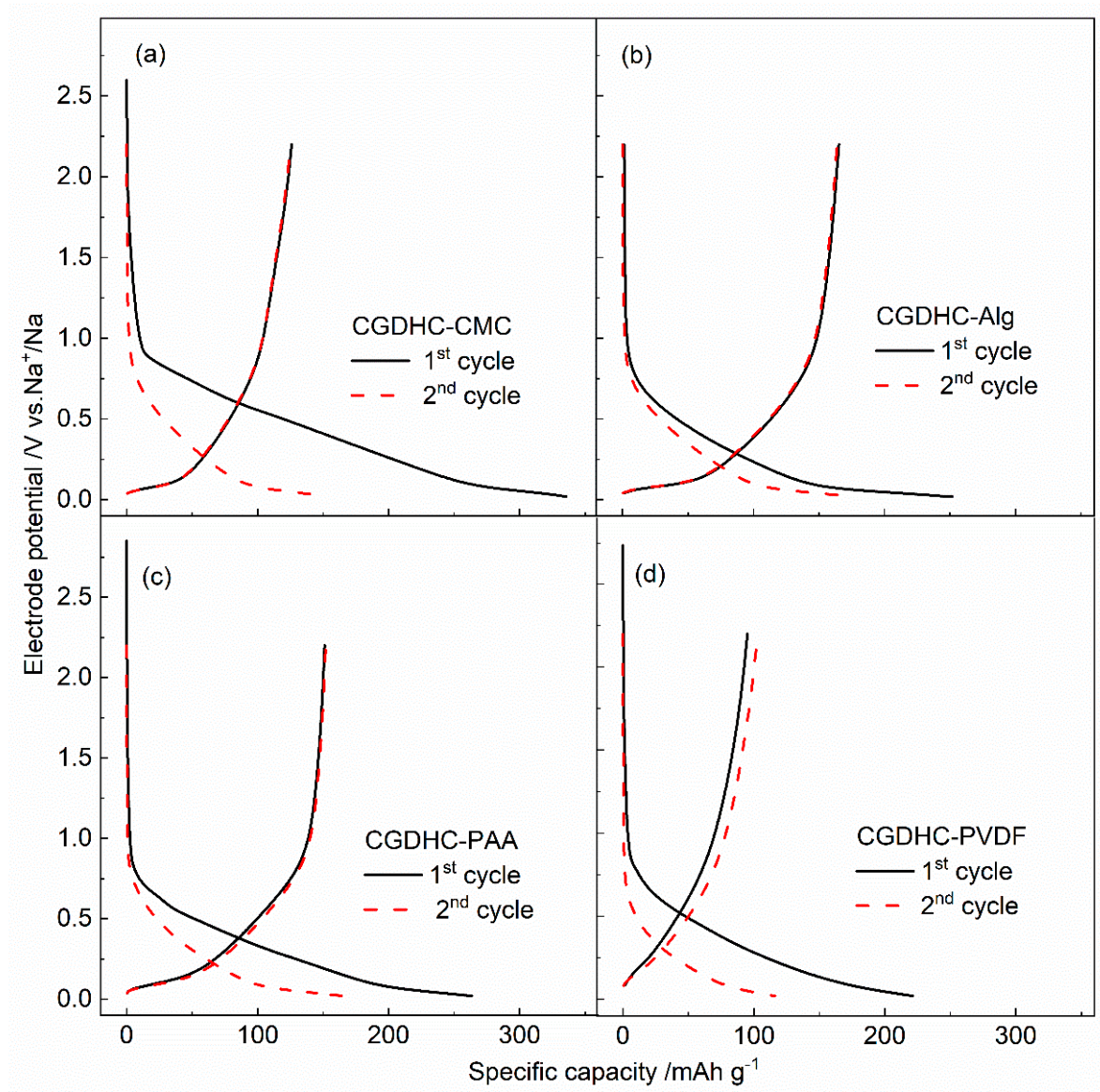

Figure 10. E vs. Q galvanostatic profiles, acquired during the first and second cycles, of CGDHC-based NIB electrodes prepared with different binders: (a) Na-carboxymethyl cellulose (CMC); (b) alginate (Alg); (c) polyacrylic acid (PAA); (d) poly(vinylidene difluoride) (PVDF). Cycling rate C/5.

Therefore, the coulombic efficiency of CGDHC-Alg and CGDHC-PAA electrodes is higher than those of CGDHC-CMC and CGDHC-PVDF. The irreversible capacity loss in NIBs is due to the formation of SEI film, which results in the decomposition of the electrolyte, and irreversible reactions include the reaction between $\mathrm{Na}$ and surface functional groups and the sodium insertion into special defect positions [30].

As shown in Figure 11, among the four electrodes prepared with different binders, the CGDHC-Alg demonstrates promising performances in NIBs, with a reversible discharge capacity of $173.51 \mathrm{mAh} \mathrm{g}^{-1}$ at $C / 5$ between 0.02 and $2.20 \mathrm{~V}$, and an excellent capacity retention of $98 \%$ after 100 cycles. This behavior can be related to the retained structural and morphological integrity of active material and interface upon sodiation and desodiation [44], because of the strong binding between active materials and the alginate binder, and the weak but effective hydrogen-bonding between $-\mathrm{OH}$ groups of active material and $-\mathrm{COOH}$ groups of the alginate binder [44]. A contribution to the better electrochemical performance of Alg-CGDHC electrode can also be related to the more homogenous morphology, as shown in SEM images. The discharge capacity and capacity retention at $0.2 \mathrm{C}$ for 
CGDHC-PAA, CGDHC-CMC, CGDHC-PVDF electrodes are instead poorer, resulting in 138.05, 118.65, and $88.44 \mathrm{mAh} \mathrm{g}^{-1}$, corresponding to a capacity retention of $83.7 \%, 77.7 \%$, and $76.3 \%$, respectively, after 100 cycles. Nevertheless, the electrode prepared with PAA shows a higher discharge capacity and a better cyclability in comparison to those made with CMC or PVDF, which can be ascribed to the suitable swelling property, a more uniformly and thin passivation film upon sodiation that results in a more stable SEI film, a better electrical contact between the particles and $\mathrm{Al}$ current collector, and a better ionic conductivity on the surface of active materials [30].

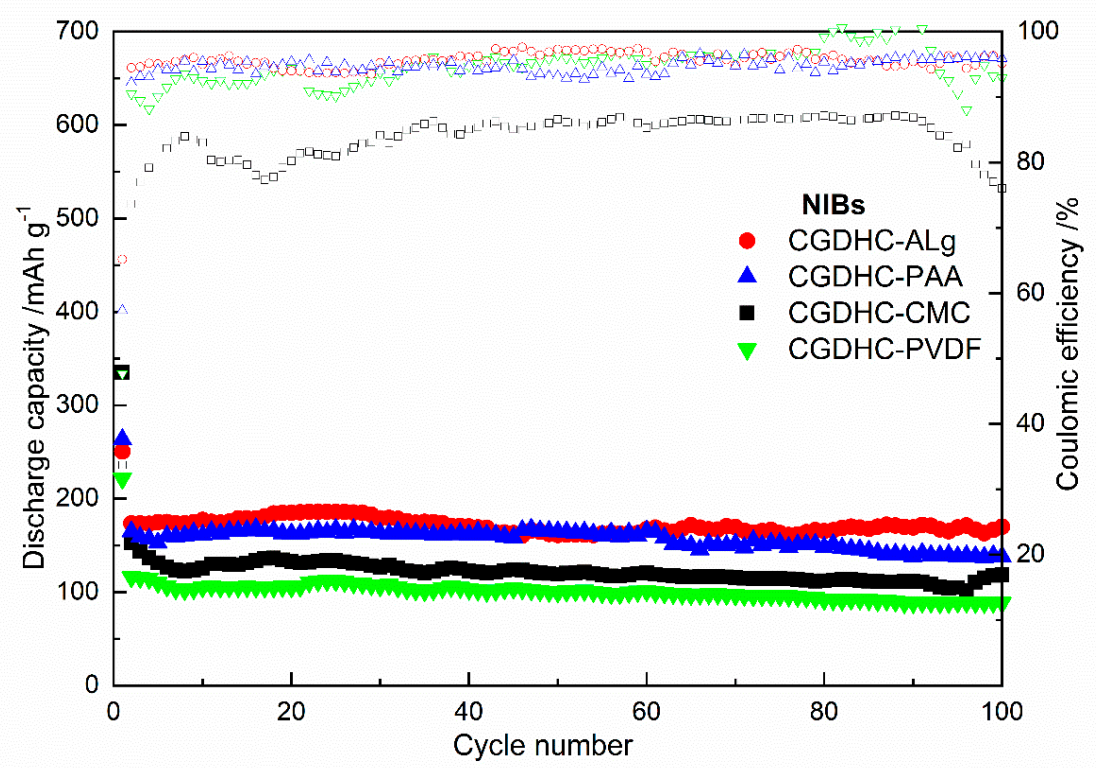

Figure 11. Cycle performance of CGDHC-based NIB electrodes with different binders. Cycling rate C/5.

In contrast, the inferior electrochemical properties of CGDHC-PVDF in NIBs can be related to the formation of $\mathrm{NaF}$ due to the formation of thick films and of the binder di-fluorination [47].

In order to validate the effect of the interfacial properties toward the electrochemical behavior, electrochemical impedance spectroscopy (EIS) was carried out for each tenth cycle at $\mathrm{E}=0.5 \mathrm{~V}$ for NIBs as well. The Nyquist plots are shown in Figure 12a-d. During the first cycle, the ac-impedance diagrams show a different behavior with respect to following cycles, because of electrode activation. The data were modeled by using the same equivalent circuit proposed for LIBs. According to the fit results (shown in Figure S5), the Alg-based electrode exhibited lower and almost constant charge transfer resistance values upon cycling, confirming its interfacial behavior stability. In contrast, the PVDF-based electrode demonstrates a much higher $\mathrm{R}_{\mathrm{ct}}$, which causes worse cycling behavior with respect to other electrodes. This can be related to the cracks formed on the electrode, as revealed by SEM.

The performances obtained, which are summarized in Tables 2 and 3, are comparable to those reported in literature for several types of hard carbon electrode materials (Table S2). This demonstrates the feasibility of a hard carbon material obtained by a coffee ground precursor as a low cost and environmentally friendly, active material for advanced negative electrodes for both LIBs and NIBs. 


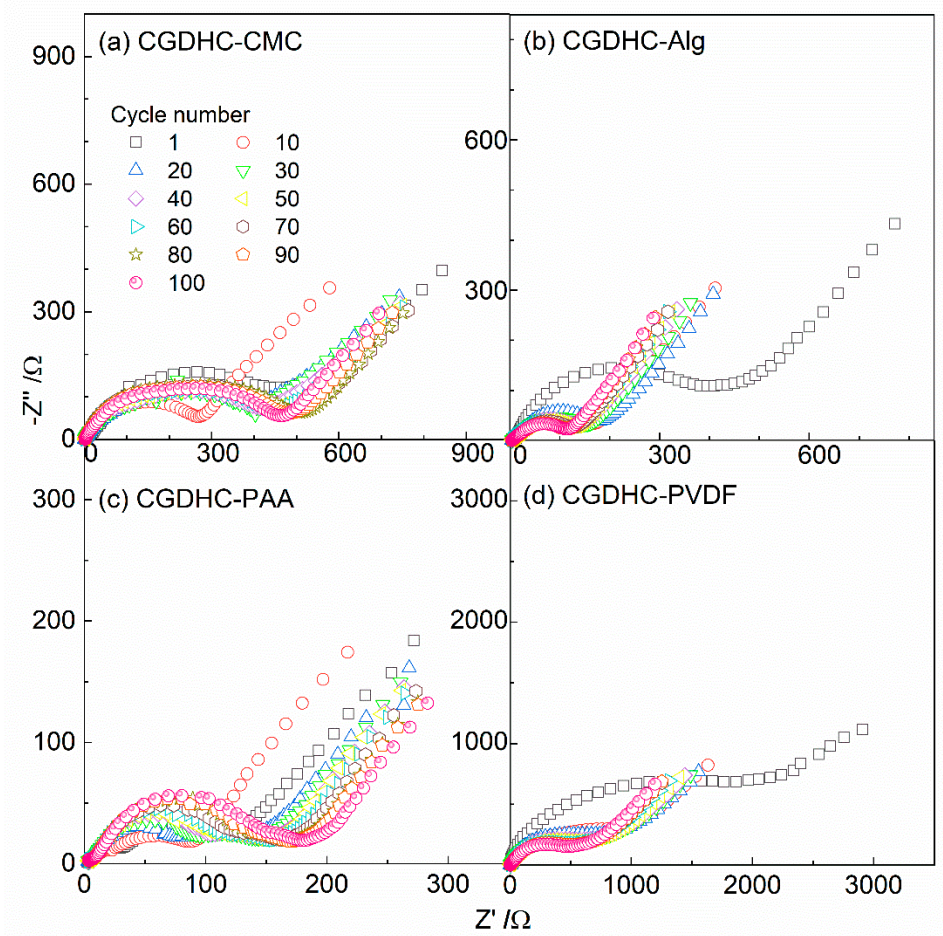

Figure 12. Nyquist plot of CGDHC-based NIB electrodes prepared with different binders: (a) Na-carboxymethyl cellulose (CMC); (b) alginate (Alg); (c) polyacrylic acid (PAA); (d) poly(vinylidene difluoride) (PVDF). $\mathrm{E}=0.5 \mathrm{~V} ; 10 \mathrm{mHz}<\mathrm{f}<100 \mathrm{kHz}$.

Table 2. Values of initial irreversible discharge capacity, initial reversible discharge capacity, capacity retention, and coulombic efficiency of CGDHC-based LIB electrodes. Cycling rate C/5.

\begin{tabular}{|c|c|c|c|c|c|}
\hline Samples & $\begin{array}{c}\text { First } \\
\text { Discharge } \\
\text { Capacity } \\
\left(\mathrm{mAh} \mathrm{g}^{-1}\right)\end{array}$ & $\begin{array}{c}\text { First } \\
\text { Charge } \\
\text { Capacity } \\
\left(\mathrm{mAh} \mathrm{g}^{-1}\right)\end{array}$ & $\begin{array}{l}\text { Coulombic } \\
\text { Efficiency }\end{array}$ & $\begin{array}{c}\text { Second } \\
\text { Discharge } \\
\text { Capacity } \\
\left(\mathrm{mAh} \mathrm{g}^{-1}\right)\end{array}$ & $\begin{array}{c}\text { Capacity } \\
\text { Retention } \\
\text { after } 100 \\
\text { Cycles }\end{array}$ \\
\hline CGDHC-CMC & 732.4 & 399.1 & $54 \%$ & 421.8 & $70.0 \%$ \\
\hline CGDHC-Alg & 616.0 & 346.3 & $56 \%$ & 360.2 & $72.8 \%$ \\
\hline CGDHC-PAA & 581.3 & 330.7 & $57 \%$ & 350.3 & $76.3 \%$ \\
\hline CGDHC-PVDF & 582.6 & 326.5 & $56 \%$ & 350.1 & $73.7 \%$ \\
\hline
\end{tabular}

Table 3. Values of initial irreversible discharge capacity, initial reversible discharge capacity, capacity retention, and coulombic efficiency of CGDHC-based NIB electrodes. Cycling rate C/5.

\begin{tabular}{|c|c|c|c|c|c|}
\hline Samples & $\begin{array}{c}\text { First } \\
\text { Discharge } \\
\text { Capacity } \\
\left(\mathrm{mAh} \mathrm{g}^{-1}\right)\end{array}$ & $\begin{array}{c}\text { First } \\
\text { Charge } \\
\text { Capacity } \\
\left(\mathrm{mAh} \mathrm{g}^{-1}\right)\end{array}$ & $\begin{array}{l}\text { Coulombic } \\
\text { Efficiency }\end{array}$ & $\begin{array}{c}\text { Second } \\
\text { Discharge } \\
\text { Capacity } \\
\left(\mathrm{mAh} \mathrm{g}^{-1}\right)\end{array}$ & $\begin{array}{c}\text { Capacity } \\
\text { Retention } \\
\text { after } 100 \\
\text { Cycles }\end{array}$ \\
\hline CGDHC-CMC & 335.5 & 113.0 & $34 \%$ & 152.6 & $77.7 \%$ \\
\hline CGDHC-Alg & 250.4 & 163.2 & $65 \%$ & 173.5 & $98.0 \%$ \\
\hline CGDHC-PAA & 263.3 & 151.0 & $57 \%$ & 164.8 & $83.7 \%$ \\
\hline CGDHC-PVDF & 221.3 & 105.5 & $47 \%$ & 115.9 & $76.3 \%$ \\
\hline
\end{tabular}

\section{Conclusions}

We have shown the synthesis of hard carbon material from a widely available food waste, with a focus on understanding the impact of binders on the behavior of electrodes based on hard carbon derived from coffee grounds. The crystallographic parameters indicate a certain degree of graphitization besides 
a disordered structure of CGDHC hard carbon. It was shown that the binder makes an important contribution to the electrochemical performance for LIBs and NIBs. Changing over from commercial PVDF binder to aqueous binders is becoming increasingly important in the production of greener batteries. According to the electrochemical results, although the hard carbon electrode with CMC binder showed highest reversible discharge capacity of $421.86 \mathrm{mAh} \mathrm{g}^{-1}$, the PAA-based electrode exhibited better capacity retention than those with other binders. The CGDHC based on water soluble binders not only showed excellent capacity and cycling performance of the Li-ion battery, but also could decrease environmental impact and cost, and is easier to use for the electrode preparation process. This also holds true for NIBs, which are in their early stage of improvement in the research; the electrode utilizing alginate presented a much enhanced performance with a capacity of $173.51 \mathrm{mAh} \mathrm{g}^{-1}$, and an excellent cycling performance of $98 \%$ after 100 cycles. This work is beneficial and provides a way to the synthesis and the utilization of low cost, greener, and sustainable electrode materials (hard carbons derived from a wide range of food wastes together with the utilization of bioderived, aqueous binders), assessing the feasibility of application in both LIBs and NIBs with state-of-the-art performance.

Supplementary Materials: Supplementary Materials can be found at http://www.mdpi.com/1996-1073/13/23/ 6216/s1.

Author Contributions: Conceptualization: H.D. and F.N.; methodology: H.D.; experimental activity: H.D., L.S., L.B., R.T., A.S.; data analysis: H.D. and F.N.; writing - original draft preparation, H.D.; writing-review and editing, H.D. and F.N.; supervision, F.N. All authors have read and agreed to the published version of the manuscript.

Funding: This research received no external funding.

Acknowledgments: This research was funded by ENEA (Agenzia Nazionale per le Nuove Tecnologie, l'Energia e lo Sviluppo Sostenibile) and MiSE (Ministero per lo Sviluppo Economico). Project: "Sistemi di Accumulo di Energia per il Sistema Elettrico" in the framework of PTR Program of ENEA/MiSE.

Conflicts of Interest: The authors declare no conflict of interest.

\section{References}

1. Zhao, C.; Huang, Y.; Zhao, C.; Shao, X.; Zhu, Z. Rose-derived 3D carbon nanosheets for high cyclability and extended voltage supercapacitors. Electrochim. Acta 2018, 291, 287-296. [CrossRef]

2. Xiang, J.; Lv, W.; Mu, C.; Zhao, J.; Wang, B. Activated hard carbon from orange peel for lithium/sodium ion battery anode with long cycle life. J. Alloys Compd. 2017, 701, 870-874. [CrossRef]

3. Darjazi, H.; Hosseiny Davarani, S.S.; Moazami, H.R.; Yousefi, T.; Tabatabaei, F. Evaluation of charge storage ability of chrome doped $\mathrm{Mn} 2 \mathrm{O} 3$ nanostructures derived by cathodic electrodeposition. Prog. Nat. Sci. Mater. Int. 2016, 26, 523-527. [CrossRef]

4. Notohara, H.; Urita, K.; Moriguchi, I. Tin Oxide Electrodes in Li and Na-Ion Batteries; Elsevier Inc.: Amsterdam, The Netherlands, 2020; ISBN 9780128159248.

5. Nitta, N.; Wu, F.; Lee, J.T.; Yushin, G. Li-ion battery materials: Present and future. Mater. Today 2015, 18, 252-264. [CrossRef]

6. Eilers-Rethwisch, M.; Hildebrand, S.; Evertz, M.; Ibing, L.; Dagger, T.; Winter, M.; Schappacher, F.M. Comparative study of Sn-doped $\mathrm{Li}\left[\mathrm{Ni}_{0.6} \mathrm{Mn}_{0.2} \mathrm{Co}_{0.2-\mathrm{x}} \mathrm{Sn}_{\mathrm{x}}\right] \mathrm{O}_{2}$ cathode active materials $(\mathrm{x}=0-0.5)$ for lithium ion batteries regarding electrochemical performance and structural stability. J. Power Sources 2018, 397, 68-78. [CrossRef]

7. Hou, H.; Shao, L.; Zhang, Y.; Zou, G.; Chen, J.; Ji, X. Large-Area Carbon Nanosheets Doped with Phosphorus: A High-Performance Anode Material for Sodium-Ion Batteries. Adv. Sci. 2017, 4. [CrossRef]

8. Wang, N.; Liu, Q.; Sun, B.; Gu, J.; Yu, B.; Zhang, W.; Zhang, D. N-doped catalytic graphitized hard carbon for high-performance lithium/sodium-ion batteries. Sci. Rep. 2018, 8, 1-8. [CrossRef]

9. Zhao, Q.; Lu, Y.; Chen, J. Advanced Organic Electrode Materials for Rechargeable Sodium-Ion Batteries. Adv. Energy Mater. 2017, 7. [CrossRef]

10. Kang, H.; Liu, Y.; Cao, K.; Zhao, Y.; Jiao, L.; Wang, Y.; Yuan, H. Update on anode materials for Na-ion batteries. J. Mater. Chem. A 2015, 3, 17899-17913. [CrossRef] 
11. Balogun, M.S.; Luo, Y.; Qiu, W.; Liu, P.; Tong, Y. A review of carbon materials and their composites with alloy metals for sodium ion battery anodes. Carbon N. Y. 2016, 98, 162-178. [CrossRef]

12. Jache, B.; Binder, J.O.; Abe, T.; Adelhelm, P. A comparative study on the impact of different glymes and their derivatives as electrolyte solvents for graphite co-intercalation electrodes in lithium-ion and sodium-ion batteries. Phys. Chem. Chem. Phys. 2016, 18, 14299-14316. [CrossRef] [PubMed]

13. Li, Y.; Hu, Y.S.; Li, H.; Chen, L.; Huang, X. A superior low-cost amorphous carbon anode made from pitch and lignin for sodium-ion batteries. J. Mater. Chem. A 2015, 4, 96-104. [CrossRef]

14. Li, H.; Shen, F.; Luo, W.; Dai, J.; Han, X.; Chen, Y.; Yao, Y.; Zhu, H.; Fu, K.; Hitz, E.; et al. Carbonized-leaf Membrane with Anisotropic Surfaces for Sodium-ion Battery. ACS Appl. Mater. Interfaces 2016, 8, 2204-2210. [CrossRef] [PubMed]

15. Wu, L.; Buchholz, D.; Vaalma, C.; Giffin, G.A.; Passerini, S. Apple-Biowaste-Derived Hard Carbon as a Powerful Anode Material for Na-Ion Batteries. ChemElectroChem 2016, 3, 292-298. [CrossRef]

16. Lotfabad, E.M.; Ding, J.; Cui, K.; Kohandehghan, A.; Kalisvaart, W.P.; Hazelton, M.; Mitlin, D. High-density sodium and lithium ion battery anodes from banana peels. ACS Nano 2014, 8, 7115-7129. [CrossRef] [PubMed]

17. Väli, R.; Jänes, A.; Thomberg, T.; Lust, E. Synthesis and characterization of D-glucose derived nanospheric hard carbon negative electrodes for lithium- and sodium-ion batteries. Electrochim. Acta 2017, 253, 536-544. [CrossRef]

18. Ding, J.; Wang, H.; Li, Z.; Kohandehghan, A.; Cui, K.; Xu, Z.; Zahiri, B.; Tan, X.; Lotfabad, E.M.; Olsen, B.C.; et al. Carbon nanosheet frameworks derived from peat moss as high performance sodium ion battery anodes. ACS Nano 2013, 7, 11004-11015. [CrossRef]

19. Lv, W.; Wen, F.; Xiang, J.; Zhao, J.; Li, L.; Wang, L.; Liu, Z.; Tian, Y. Peanut shell derived hard carbon as ultralong cycling anodes for lithium and sodium batteries. Electrochim. Acta 2015, 176, 533-541. [CrossRef]

20. Li, Y.; Hu, Y.S.; Titirici, M.M.; Chen, L.; Huang, X. Hard Carbon Microtubes Made from Renewable Cotton as High-Performance Anode Material for Sodium-Ion Batteries. Adv. Energy Mater. 2016, 6. [CrossRef]

21. Dou, X.; Hasa, I.; Saurel, D.; Vaalma, C.; Wu, L.; Buchholz, D.; Bresser, D.; Komaba, S.; Passerini, S. Hard carbons for sodium-ion batteries: Structure, analysis, sustainability, and electrochemistry. Mater. Today 2019, 23, 87-104. [CrossRef]

22. Saurel, D.; Orayech, B.; Xiao, B.; Carriazo, D.; Li, X.; Rojo, T. From Charge Storage Mechanism to Performance: A Roadmap toward High Specific Energy Sodium-Ion Batteries through Carbon Anode Optimization. Adv. Energy Mater. 2018, 8, 1-33. [CrossRef]

23. Velez, V.; Ramos-Sánchez, G.; Lopez, B.; Lartundo-Rojas, L.; González, I.; Sierra, L. Synthesis of novel hard mesoporous carbons and their application as anodes for Li and Na ion batteries. Carbon N. Y. 2019, 147, 214-226. [CrossRef]

24. Dachowski, R.; Kostrzewa, P. The Use of Waste Materials in the Construction Industry. Procedia Eng. 2016, 161, 754-758. [CrossRef]

25. Wang, R.; Feng, L.; Yang, W.; Zhang, Y.; Zhang, Y.; Bai, W.; Liu, B.; Zhang, W.; Chuan, Y.; Zheng, Z.; et al. Effect of Different Binders on the Electrochemical Performance of Metal Oxide Anode for Lithium-Ion Batteries. Nanoscale Res. Lett. 2017, 12. [CrossRef]

26. Zhang, Z.; Zeng, T.; Lai, Y.; Jia, M.; Li, J. A comparative study of different binders and their effects on electrochemical properties of $\mathrm{LiMn}_{2} \mathrm{O}_{4}$ cathode in lithium ion batteries. J. Power Sources 2014, 247, 1-8. [CrossRef]

27. Yoo, M.; Frank, C.W.; Mori, S.; Yamaguchi, S. Effect of poly(vinylidene fluoride) binder crystallinity and graphite structure on the mechanical strength of the composite anode in a lithium ion battery. Polymer 2003, 44, 4197-4204. [CrossRef]

28. Xu, J.; Chou, S.L.; Gu, Q.F.; Liu, H.K.; Dou, S.X. The effect of different binders on electrochemical properties of $\mathrm{LiNi}_{1 / 3} \mathrm{Mn}_{1 / 3} \mathrm{Co}_{1 / 3} \mathrm{O}_{2}$ cathode material in lithium ion batteries. J. Power Sources 2013, 225, 172-178. [CrossRef]

29. Chou, S.L.; Pan, Y.; Wang, J.Z.; Liu, H.K.; Dou, S.X. Small things make a big difference: Binder effects on the performance of Li and Na batteries. Phys. Chem. Chem. Phys. 2014, 16, 20347-20359. [CrossRef]

30. Fan, Q.; Zhang, W.; Duan, J.; Hong, K.; Xue, L.; Huang, Y. Effects of binders on electrochemical performance of nitrogen-doped carbon nanotube anode in sodium-ion battery. Electrochim. Acta 2015, 174, 970-977. [CrossRef] 
31. Beda, A.; Taberna, P.; Simon, P.; Ghimbeu, C.M.; Beda, A.; Taberna, P.; Simon, P.; Matei, C.; Hard, G. Hard carbons derived from green phenolic resins for Na-ion batteries To cite this version: HAL Id: Hal-02022742. Carbon 2018, 139, 248-257. [CrossRef]

32. Zhu, X.; Jiang, X.; Liu, X.; Xiao, L.; Cao, Y. A green route to synthesize low-cost and high-performance hard carbon as promising sodium-ion battery anodes from sorghum stalk waste. Green Energy Environ. 2017, 2, 310-315. [CrossRef]

33. Li, Y.; Ni, B.; Li, X.; Wang, X.; Zhang, D.; Zhao, Q.; Li, J.; Lu, T.; Mai, W.; Pan, L. High-Performance Na-Ion Storage of S-Doped Porous Carbon Derived from Conjugated Microporous Polymers. Nano-Micro Lett. 2019, 11, 1-13. [CrossRef]

34. Luo, C.; Fan, X.; Ma, Z.; Gao, T.; Wang, C. Self-Healing Chemistry between Organic Material and Binder for Stable Sodium-Ion Batteries. Chem 2017, 3, 1050-1062. [CrossRef]

35. Tang, W.; Zhang, Y.; Zhong, Y.; Shen, T.; Wang, X.; Xia, X.; Tu, J. Natural biomass-derived carbons for electrochemical energy storage. Mater. Res. Bull. 2017, 88, 234-241. [CrossRef]

36. Ajuria, J.; Redondo, E.; Arnaiz, M.; Mysyk, R.; Rojo, T.; Goikolea, E. Lithium and sodium ion capacitors with high energy and power densities based on carbons from recycled olive pits. J. Power Sources 2017, 359, 17-26. [CrossRef]

37. Ni, J.; Huang, Y.; Gao, L. A high-performance hard carbon for Li-ion batteries and supercapacitors application. J. Power Sources 2013, 223, 306-311. [CrossRef]

38. Dell'Era, A.; Pasquali, M.; Tarquini, G.; Scaramuzzo, F.A.; De Gasperis, P.; Prosini, P.P.; Mezzi, A.; Tuffi, R.; Cafiero, L. Carbon powder material obtained from an innovative high pressure water jet recycling process of tires used as anode in alkali ion (Li, Na) batteries. Solid State Ion. 2018, 324, 20-27. [CrossRef]

39. Wang, H.; Umeno, T.; Mizuma, K.; Yoshio, M. Highly conductive bridges between graphite spheres to improve the cycle performance of a graphite anode in lithium-ion batteries. J. Power Sources 2008, 175, 886-890. [CrossRef]

40. García, A.; Culebras, M.; Collins, M.N.; Leahy, J.J. Stability and rheological study of sodium carboxymethyl cellulose and alginate suspensions as binders for lithium ion batteries. J. Appl. Polym. Sci. 2018, 135, 11-13. [CrossRef]

41. Guerfi, A.; Kaneko, M.; Petitclerc, M.; Mori, M.; Zaghib, K. $\mathrm{LiFePO}_{4}$ water-soluble binder electrode for Li-ion batteries. J. Power Sources 2007, 163, 1047-1052. [CrossRef]

42. Komaba, S.; Okushi, K.; Ozeki, T.; Yui, H.; Katayama, Y.; Miura, T.; Saito, T.; Groult, H. Polyacrylate modifier for graphite anode of lithium-ion batteries. Electrochem. Solid-State Lett. 2009, 12, 107-110. [CrossRef]

43. Nobili, F.; Dsoke, S.; Mancini, M.; Tossici, R.; Marassi, R. Electrochemical investigation of polarization phenomena and intercalation kinetics of oxidized graphite electrodes coated with evaporated metal layers. J. Power Sources 2008, 180, 845-851. [CrossRef]

44. Feng, J.; Wang, L.; Li, D.; Lu, P.; Hou, F.; Liang, J. Enhanced electrochemical stability of carbon-coated antimony nanoparticles with sodium alginate binder for sodium-ion batteries. Prog. Nat. Sci. Mater. Int. 2018, 28, 205-211. [CrossRef]

45. Zarrabeitia, M.; Nobili, F.; Muñoz-Márquez, M.Á.; Rojo, T.; Casas-Cabanas, M. Direct observation of electronic conductivity transitions and solid electrolyte interphase stability of $\mathrm{Na}_{2} \mathrm{Ti}_{3} \mathrm{O}_{7}$ electrodes for $\mathrm{Na}$-ion batteries. J. Power Sources 2016, 330, 78-83. [CrossRef]

46. Zarrabeitia, M.; Muñoz-Márquez, M.Á.; Nobili, F.; Rojo, T.; Casas-Cabanas, M. Influence of using metallic na on the interfacial and transport properties of Na-Ion batteries. Batteries 2017, 3, 16. [CrossRef]

47. Bresser, D.; Buchholz, D.; Moretti, A.; Varzi, A.; Passerini, S. Alternative binders for sustainable electrochemical energy storage-the transition to aqueous electrode processing and bio-derived polymers. Energy Environ. Sci. 2018, 11, 3096-3127. [CrossRef]

Publisher's Note: MDPI stays neutral with regard to jurisdictional claims in published maps and institutional affiliations. 